\title{
BIBLIOMETRIC REVIEW ON THE EDUCATION OF PEOPLE WITH AUTISM SPECTRUM DISORDER WITHOUT ASSOCIATED DISABILITY
}

\author{
Paola Melero-Pérez, \& Marcos Gómez-Puerta \\ Department of Developmental Psychology and Teaching, University of Alicante (Spain)
}

\begin{abstract}
Throughout the last decades, the number of published studies addressing the schooling of students with autism spectrum disorder (ASD) has increased significantly. The aim of our study is to conduct a bibliometric review in the Scopus database on published and indexed research that addresses the schooling and training of students with ASD without associated intellectual disability. The selected studies in the field of education and psychology were 500. The results have shown an increase in productivity, decreasing notably in 2018. With respect to the computation of journals that publish content on ASD, The Journal Research in ASD is highlighted. In addition, a tendency to write in collaboration has been observed, being equal the number of publications by each of the authors. In conclusion, it has been pointed out that with regard to the subject, the perspective of the people with ASD is not taken into account, but rather that it is investigated from a professional and theoretical point of view. That is why we propose some future lines of research from the voice of the families and people with ASD.
\end{abstract}

Keywords: Bibliometrics, Autism spectrum disorder, special education.

\section{Introduction}

According to the American Psychiatric Association (APA, 2013), the Autism Spectrum Disorder (ASD) hinders the social relations of the individual with society, since it affects the way of seeing the world and as a consequence, it hinders the processing of information. It should be noted that there is a great heterogeneity in people with ASD. According to the DSM-V, the main characteristic of these people is the deficiency in the socio-emotional reciprocity (verbal and non-verbal) in any communicative situation. In turn, in most cases there are stereotypes, that is, repetitive patterns such as movement, inflexibility of routines, very fixed interests...

The panorama of research on students with ASD is very broad and diverse, since it has been studied from different approaches, although through a quantitative methodology in most cases (Rica, Rica, José, \& Rica, 2007). As noted in the results section, most of the studies are from a medical and psychological perspective. In the educational area, several studies have been developed from a cognitive point of view, regarding the level of learning and adaptation to the environment. These studies collected data mainly from samples of teaching staff and family members (Villegas, Simon, \& Echeita, 2014).

The main objective of the Salamanca Declaration was that its writing should serve as a reference for the planning of future actions on special education needs, and indicated that the framework for action was at the international level, since each country and region should adapt these guidelines to its concrete context (Declaration of Salamanca, 1994).

Recently, the voice of families and students with ASD is begin considered as valuable data, especially in studies related to transitions from compulsory education to the university or to employment. The main approach on these studies is qualitative which are focused on specific aspects such as changes and school anxiety (First, Cheak-Zamora, \& Teti, 2016). Parallel to this, the number of people diagnosed with ASD has increased considerably in recent years (White et al., 2016).

While it is true that there are some bibliometric studies on scientific literature on ASD (eg. McDonald \& Machalicek, 2013), there are scarce studies on this topic which consider that ASD can be associated to other disabilities, mainly with intellectual disability. Those, the main objective of this study is to perform a bibliometric review on research publications on people with ASD without intellectual disability. In this review, it has been established as starting point 1995 since this year marks the entry into force of the Salamanca Declaration. This Declaration marked the beginning of an inclusive 
era in schools. To achieve this goal, we will made a bibliometric in the Scopus database about ASD without associated disability to offer a global image of the current state of research. It is therefore, we will take into account the following variables: evolution over time, productivity of journals, documentary typology and number of authors in each publications.

\section{Method}

\subsection{Participants}

In this study, 500 documents indexed in the Scopus database were analyzed. These publications are located in a range of 24 years, from 1995 until 2018, both included.

\subsection{Instruments}

The instrument used is the Scopus database due to its large volume of data and its international and multidisciplinary prestige.

\subsection{Process}

The search strategy used was as follows: autism AND (school OR education) AND (adolescent * OR teen *)) AND (PUBYEAR> 1995) AND NOT (handicap * OR disabilit *) AND LIMIT-TO (SUBJAREA, "PSYC") OR LIMIT-TO (SUBJAREA, "SOCI") OR LIMIT-TO (SUBJAREA, "COMP") OR LIMIT-TO (SUBJAREA, "MULT"). As can be seen, the search was limited from the first publication of the year 1995 until the last writing published in December 2018. Through this strategy a total of 733 articles were found. Nevertheless, 233 papers were not about the education field and so they were excluded of this review. The majority of these excluded studies were related to the medical field.

A content analysis was made for the selection of the sample, in order to discard those studies which were not related to the educational field. After this, the descriptive analysis was carried out based on the following variables: year of publication, number of authors, journal in which it was published and type of document published.

\section{Results}

\subsection{Evolution over time}

As we can see in figure 1, in this study we are analyzing documents from 1995 to 2018 both years included. That is why we emphasize that the range of publications per year ranges from 0 to 95 documents, with an average of 21.7 articles per year. It should be noted that in 1998 there was no publication on Autism and education, in addition, at 2008 more publications on this topic have begun to be published, with the maximum number of writings being published in 2013, despite the fact that in the last year there has been a decline, giving rise to writings in the medical field.

Figure 1. Temporal evolution of publications.

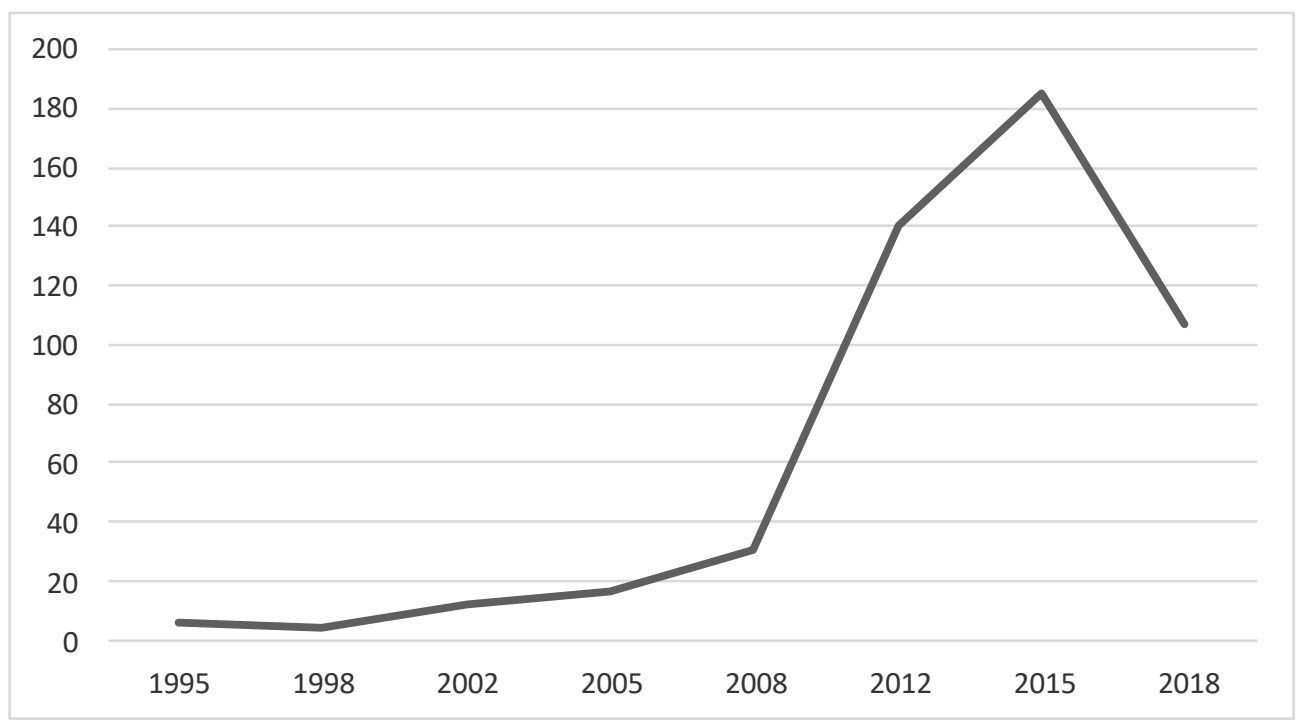




\subsection{Magazine productivity}

Figure 2 shows the journals with more publications on this subject in the Scopus database. As shown, the magazine "Research in Autism Spectrum Disorder" is that which has the most articles indexed being $55.8 \%$ of the total. In addition, we emphasize that those journals that are multidisciplinary such as "Neuropsychologia" have hardly any writings, since they belong more to the psychological and medical field.

Figure 2. Number of publications per journal.

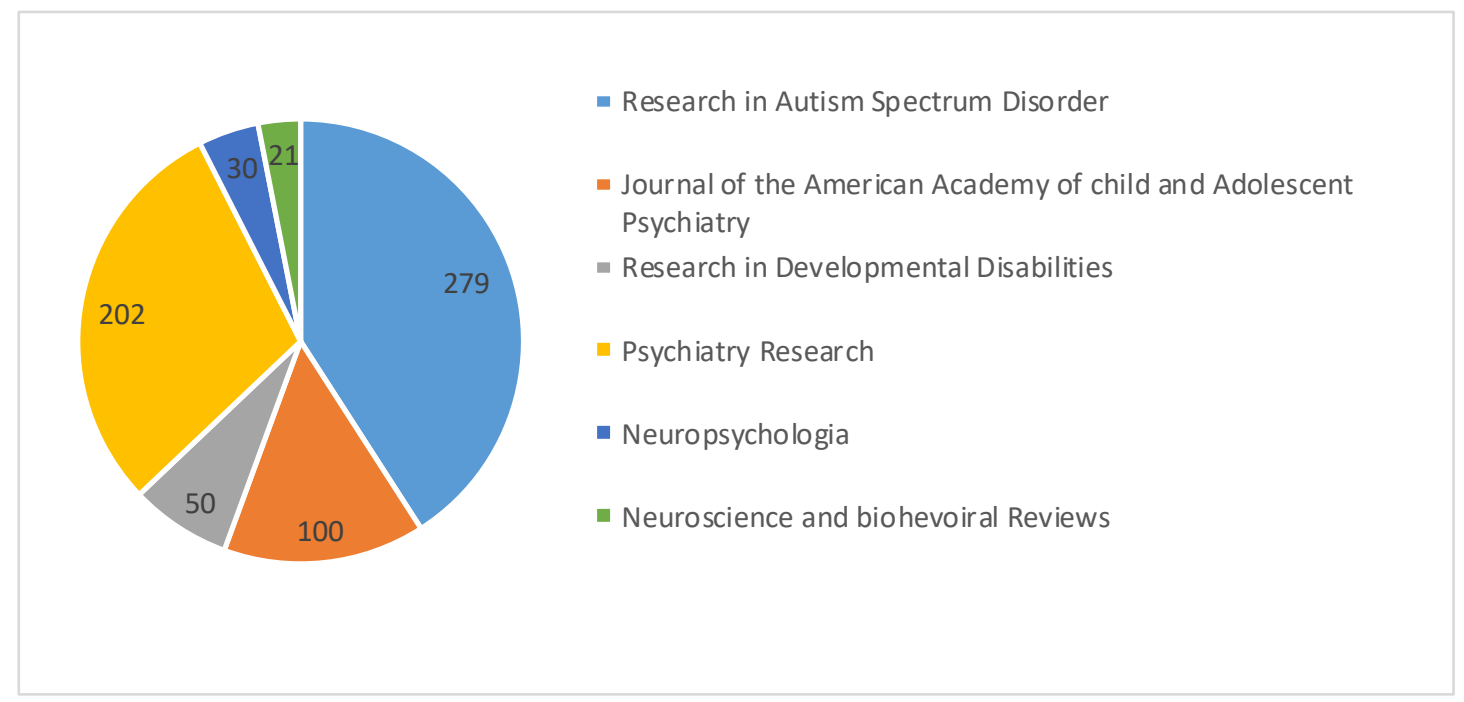

\subsection{Type of document published}

For our bibliometric study we have carried out the search of the following type of document: Review articles, research articles, conference info, data articles, mini reviews, replication studies and short communications, due to the typology of the writings. As can be seen in Figure 3, the largest number of indexed documents are research articles, in addition this type of publication has been increasing over the years, because it started publishing theoretical articles and, with the step of time, empirical studies and research itself have been carried out. On the other hand, we see how nothing has been published of different documents, an aspect that is worth highlighting.

Figure 3. Typology of documents.

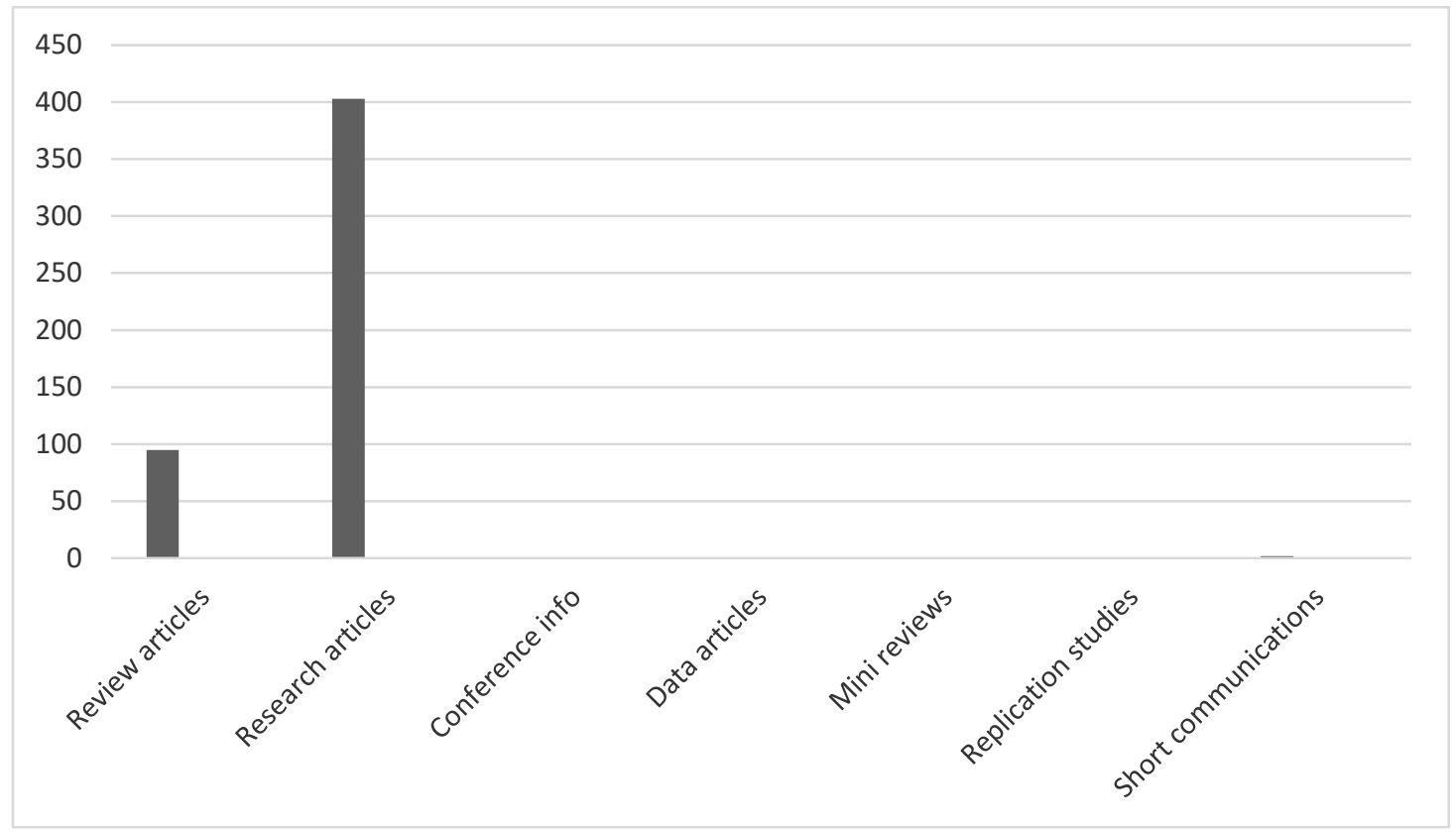




\subsection{Number of authors per document}

In Figure 4, we can see that co-authorship writing by more than four people predominates. In addition, we do not find any document that has been written individually. However, in recent years there has been an increase in writings made by three authors.

Figure 3. Evolution of the number of authors per work.

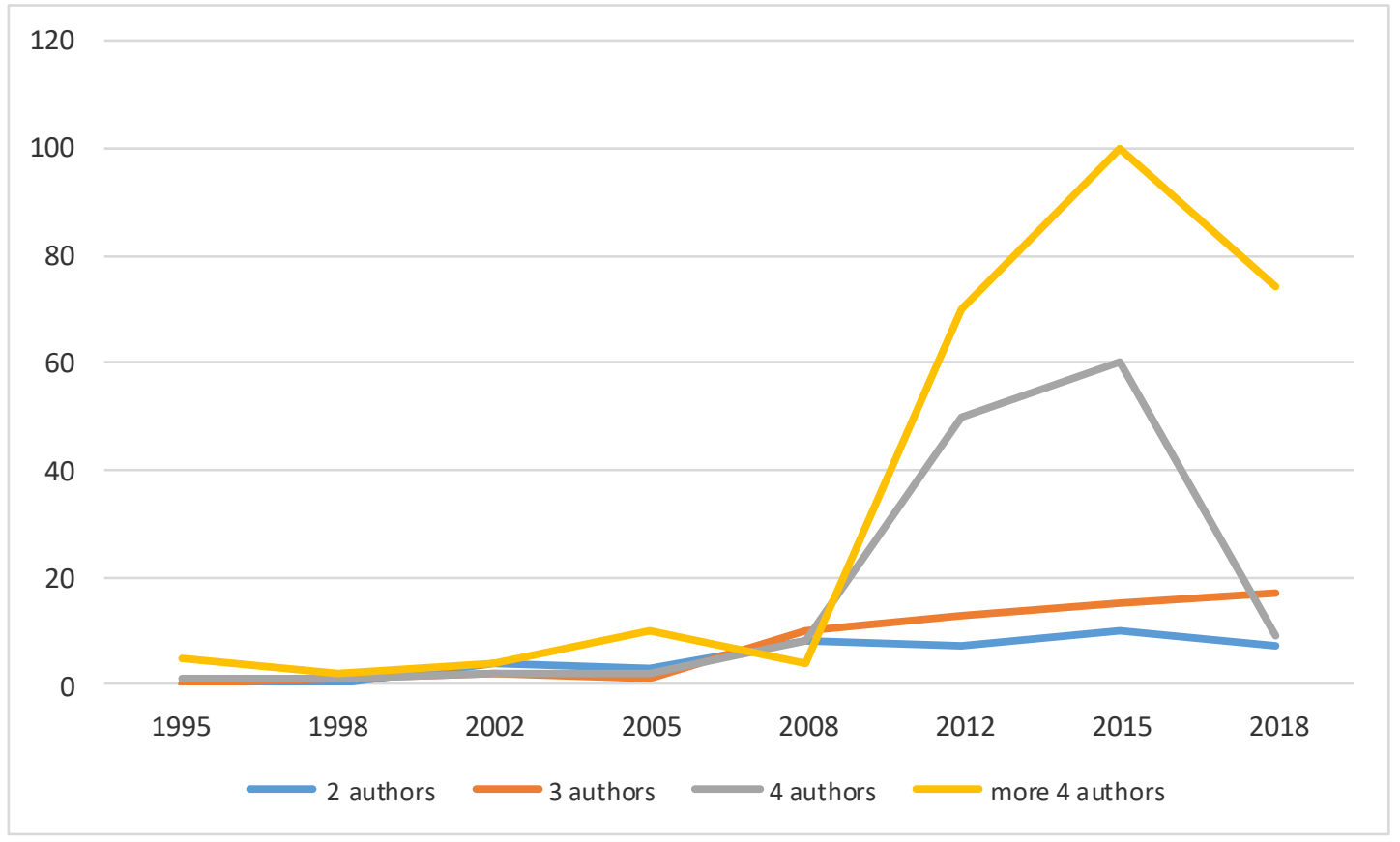

\section{Conclusions}

In the present study we have carried out a bibliometric review on the evolution of the production of articles on autism without an associated disability since the Declaration of Salamanca. Based on the data obtained, autism has had a great writing boom in the last ten years (2008-2018), highlighting that in the past year this scientific production has decreased without a justified cause. While it is true that we emphasize that since 2013 the number of children born with Autism increased, at present, it is a disability that is quite accepted in schools and in the world of research. In spite of this, at present, a great effort is being invested to discover the genetic causes of this syndrome and the reason of the great spectrum that we find, that is, of the great diversity of characteristics and affectation.

Focusing attention on the journals analyzed in this database, we must emphasize that the largest production comes from journals specialized in the subject and that belong to the field of psychology and neuroscience. The results at the author level show that there is a great consonance with respect to co-authorship and that it is an outstanding aspect since the beginning of the 21 st century, since as we have commented in the results, in the 90s there was not a great co-authorship of more than four authors.

The limitations that we have found in the course of the investigation should be highlighted in this study. On the one hand, not all the variables that can be reviewed in a bibliometric study have been analyzed due to their great variety and heterogeneity. On the other hand, we have encountered difficulties in obtaining the descriptive data from the web scopus, since it is in "renovation works" and, it was decided to make a general analysis of the subject. For future research, it could be considered to analyze other variables such as the professional scope of the authors or the specific theme of each article.

In summary, autism is a topic that has been much researched in recent years, as we have been able to deduce from what was previously reviewed. Despite the limitations found, this study offers a broad view of what has been published about autism without an associated disability since the declaration of Salamanca in the Scopus database. 


\section{References}

American Psychological Association. (2010) Publication Manual of the American Psychological Association (6th Ed.). Washington, DC: Author.

Declaration of Salamanca, June 7-10, 1994 (Spain). Declaración de Salamanca y Marco de Acción para las necesidades educativas especiales [Declaration of Salamanca and Framework for Action for special educational needs]. $\quad$ Retrieved from http://www.unesco.org/education/pdf/SALAMA_S.PDF

First, J., Cheak-Zamora, N. C., \& Teti, M. (2016). A qualitative study of stress and coping when transitioning to adulthood with autism spectrum disorder. Journal of Family Social Work, 19(3), 220-236. https://doi.org/10.1080/10522158.2016.1185074

Rica, U. D. C., Rica, U. D. C., José, S., \& Rica, C. (2007). Autismo: Estado en cuestion. [Autism: State of the art] Revista De Ciencias Sociales Autismo Infantil: El Estado De La Cuestion.

Villegas, M., Simon, C., \& Echeita, G. (2014). La inclusión educativa desde la voz de madres de estudiantes con Trastornos del Espectro Autista en una muestra chilena. [The educational inclusion from the voice of mothers of students with Autism Spectrum Disorders in a Chilean sample]. Revista Española de Discapacidad, 2, 63-82. https://doi.org/10.5569/2340- 5104.02.02.04

White, S. W.; Elias, R.; Salinas, C. E.; Capriola, N.; Conner, C. M.; Asselin, S. B.; Getzel, E. E. (2016). Students with autism spectrum disorder in college: Results from a preliminary mixed methods needs analysis. Research in Developmental Disabilities, 56, 29-40. https://doi.org/10.1016/j.ridd.2016.05.010 